\title{
A Validated Stability of Omeprazole Sodium Injection in 0.9\% Sodium Chloride and 5\% Dextrose Solutions by RP-HPLC
}

\author{
M. Sankar*, S. Arulantony \\ Post Graduate and Research Department of Chemistry, \\ Presidency College, Triplicane (Tamil Nadu), Chennai - 600 005, India
}

\begin{abstract}
A specific, accurate, precise and reproducible stability indicating investigation of RP-HPLC method has been developed for omeprazole sodium injection in 0.9\% sodium chloride and 5\% dextrose solutions. The chromatographic separation was achieved by using the Zorbax Eclipse $C_{8}$ column ( $250 \mathrm{~mm} X 4.6$ $\mathrm{mm}, 5 \mu \mathrm{m})$ with a mixture of phosphate buffer ( $p H$ 7.2): acetonitrile in the ratio of $75: 25(\mathrm{v} / \mathrm{v})$ as mobile phase at a flow rate of $1.5 \mathrm{ml} / \mathrm{min}$. The UV detection was performed at $280 \mathrm{~nm}$. It was subsequently validated according to ICH and USP guidelines. The described method was linear over the concentration range of 80-240 $\mu \mathrm{g} / \mathrm{ml}$. The specificity of the method shows that the analyte was not interfered by the presence of excipients in both $0.9 \%$ sodium chloride and 5\% dextrose solutions and the stability of the analyte after reconstitution was found stable for 24 hours in both 0.9\% sodium chloride and 5\% dextrose solutions. Robustness studies were found satisfactory; hence it proves that the method was robust. The developed method was successfully employed for the determination of omeprazole sodium injection, when it reconstituted with $0.9 \%$ sodium chloride and $5 \%$ dextrose solutions.
\end{abstract}

KEY WORDS: Omeprazole, RP-HPLC, Sodium Chloride, Dextrose, and Validation

\section{INTRODUCTION}

Omeprazole ((RS)-5-Methoxy-2-[[(4-methoxy-3, 5-dimethyl-2-pyridinyl)-methyl]sulfinyl]-1 $\mathrm{H}$ benzimidazole or $\mathrm{C}_{17} \mathrm{H}_{19} \mathrm{~N}_{3} \mathrm{O}_{3} \mathrm{~S}$ ) (Fig. 1) is widely used as proton pump inhibitor and it indicated for the conditions of dyspepsia, peptic ulcer disease (PUD), gastroesophageal reflux disease, laryngopharyngeal reflux (LPR) and Zollinger-Ellison syndrome ${ }^{1,2}$. The mechanism involves with the suppression of gastric acid secretion by specific inhibition of the $\mathrm{H}^{+} / \mathrm{K}^{+}$-ATPase in the gastric parietal cell leads to reducing the gastric acidity ${ }^{3}$. The physical characteristics show it is of white and soluble in water, DMSO and ethanol ${ }^{4}$. The literature survey reveals various methods like Spectrophotometric ${ }^{5-10}$, TLC densiometry ${ }^{11}$, HPLC $^{12-19}$,

LC/MS ${ }^{20-22}$ have been preceded for omeprazole but no method have been developed related to stability of omeprazole injection in $0.9 \%$ sodium chloride and $5 \%$ dextrose solutions. Hence, it is needed to know the stability of omeprazole injection in the solutions of $0.9 \%$ sodium chloride and $5 \%$ dextrose solutions; however it is essential to investigate a suitable RP-HPLC method for the stability of omeprazole in commercial formulations. The present method was aimed to develop a simple, rapid, precise, accurate and selective reversed phase chromatographic method to verify the omeprazole sodium stability. The proposed procedure was optimized and validated according to International Conference on Hormonization (ICH) guidelines ${ }^{23,24}$ and USP guidelines ${ }^{25}$.

\subsection{Chemicals}

\section{MATERIALS AND METHODS}

The gift sample of omeprazole sodium injection and Placebo was obtained from Caplin Point Laboratories Limited, Chennai. The HPLC grade of acetonitrile, methanol was from Qualigens Fine Chemicals, Mumbai, India. The experimental procedure was carried out completely using Millipore (Banglore, India) MilliQ-Water purifier. The chemicals of monobasic sodium phosphate (LR), Rankem; anhydrous dibasic sodium phosphate (LR), sodium chloride (AR), dextrose (AR) and phosphoric acid (AR), and other reagents of analytical reagent grade from Merck were used for the analysis.

\subsection{Instrumentation and Analytical Conditions}

The chromatographic method carried out using Agilent 1200 series HPLC equipped with DAD \& VWD detector. The omeprazole separation was achieved by using the Zorbax Eclipse $\mathrm{C}_{8}$ column $(250 \mathrm{X} 4.6$ $\mathrm{mm}, 5 \mu)$ with a mixture of phosphate buffer $(\mathrm{pH} 7.2)$ : acetonitrile in the ratio of 75:25 (v/v) as mobile phase at a flow rate of $1.5 \mathrm{ml} / \mathrm{min}$. The $\lambda_{\max }$ was monitored by UV at $280 \mathrm{~nm}$. The software of open lab software was 
used to monitor the data acquisitions and other proceedings. The run time was fixed as $18 \mathrm{~min}$. and the room was air-conditioned at temperature of $25 \pm 2{ }^{\circ} \mathrm{C}$. The freshly prepared mobile phase was vaccum filtered through a $0.45 \mu \mathrm{m}$ Millipore nylon filters and it was used for the complete analysis.

\subsection{Preparation of Phosphate Buffer}

Dissolve $0.2 \mathrm{~g}$ of monobasic sodium phosphate and $1.120 \mathrm{~g}$ of anhydrous dibasic sodium phosphate in $300 \mathrm{~mL}$ of water, mix and dilute with water to $1000 \mathrm{~mL}$; adjust the $\mathrm{pH}$ with ortho-phosphoric acid to 7.2, and filter through $0.45 \mu \mathrm{m}$ filter.

\subsection{Preparation of Standard Solutions}

Accurately weigh about $40 \mathrm{mg}$ of Omeprazole standard and transfer into a $25 \mathrm{~mL}$ volumetric flask, dissolve in suitable volume with mobile phase and make up to the final volume using the same. Transfer $5 \mathrm{~mL}$ of this above solution into $50 \mathrm{~mL}$ volumetric flask, dilute and make up to the mark with mobile phase.

\subsection{Preparation of $\mathbf{0 . 9 \%}$ Sodium Chloride Solution}

Transfer $0.9 \mathrm{~g}$ of sodium chloride into $100 \mathrm{~mL}$ volumetric flask and dissolve it in $50 \mathrm{ml}$ of water and make up to the mark using the same.

\subsection{Preparation of $5 \%$ Dextrose Solution}

Transfer $5 \mathrm{~g}$ of dextrose into $100 \mathrm{~mL}$ volumetric flask and dissolve it in $50 \mathrm{ml}$ of water and make up to the mark using the same.

\subsection{Sample}

Omeprazole sodium injection [10ml injection vial contains $40 \mathrm{mg}$ equivalent of omeprazole as omeprazole sodium].

\subsection{Placebo Sample}

Placebo injection [10 ml injection vial contains placebo mixture without drug].

\subsection{Preparation of Sample Solution ( $0.9 \% \mathrm{NaCl}$ solution)}

Take 10 numbers of sample vials and reconstitute each vial with $0.9 \% \mathrm{NaCl}$ solution. Pooled all the vials and transfer $10 \mathrm{ml}$ (equivalent to $40 \mathrm{mg}$ of omeprazole) into a $25 \mathrm{ml}$ volumetric flask and make upto mark with mobile phase. Transfer $5 \mathrm{ml}$ of the above solution to a $50 \mathrm{ml}$ standard flask and make up the volume with mobile phase.

\subsection{Preparation of Sample Solution (5\% Dextrose)}

Take 10 numbers of sample vials and reconstitutes each vial with 5\% Dextrose solution. Pooled all the vials and transfer $10 \mathrm{ml}$ (equivalent to $40 \mathrm{mg}$ of omeprazole) into a $25 \mathrm{ml}$ volumetric flask and make upto mark with mobile phase. Transfer $5 \mathrm{ml}$ of the above solution to a $50 \mathrm{ml}$ standard flask and make up the volume with mobile phase.

\subsection{Procedure for Analysis}

The following procedure was recommended for the analysis of omeprazole estimation. Inject the volume of $20 \mu \mathrm{l}$ of blank (mobile phase) and placebo once and inject the standard preparation 6 times followed by sample preparation twice into the HPLC. After the completion of injection integrate and calculate the assay of omeprazole.

\subsection{Development of the method}

\section{RESULTS AND DISCUSSION}

A simple and rapid RP-HPLC method for the estimation of omeprazole sodium injection was developed, which can be effectively employed for quality control comparative analysis. The stationary phase of Zorbax Eclipse $\mathrm{C}_{8},(250 \times 4.6 \mathrm{~mm}, 5 \mu)$ was used. The mobile phase was confirmed after conducting the different trials using phosphate buffer, methanol and acetonitrile. The proportion of phosphate buffer: methanol $(50: 50 \mathrm{v} / \mathrm{v})$ showed more asymmetric factor with poor peak shape. Hence, decided to use phosphate buffer: instead of methanol and it found that peak with short retention time. The present method was aimed to conduct the comparative stability study of omeprazole sodium injection and it need somewhat high retention time for the better separation of omeprazole from degradation or matrix peaks while conducting the stability of omeprazole sodium injection in $0.9 \%$ sodium chloride and $5 \%$ dextrose injection. The various trials were conducted with 
different proportions of phosphate buffer: acetonitrile like 50:50 v/v, 60:40 v/v, 70:30 v/v, 75:25 v/v, and 80:20 $\mathrm{v} / \mathrm{v}$. The proportion of 75:25 v/v yield a good peak shape but little peak fronting. The different $\mathrm{pH}$ conditions were used to eliminate the peak fronting by altering the $\mathrm{pH}$ from 5.0,6.0, 6.5, 7.0, 7.2, and 7.4. At $\mathrm{pH} 7.2$ the peak symmetry was achieved with for $0.9 \%$ sodium chloride was $11.147 \pm 0.12$ and $5 \%$ dextrose was to be 11.053 \pm 0.18 . The chromatograms were showed in Fig. 2A. 0.9\% Sodium chloride and Fig. 2B. 5\% dextrose. All the above studies were monitored at $280 \mathrm{~nm}$ with $1.5 \mathrm{ml} / \mathrm{min}$ flow rate. The method was found to be specific, and it shows none of the excipients interfered with the analyte of interest. Hence, the method can be successfully employed for the assay of commercially available formulations.

\subsection{Validation of the Method}

The validation of the optimized carried out method was performed according to the ICH guidelines with respect to following parameters:

\subsection{Linearity}

Linearity graph was obtained from peak area response against the injected concentrations of the drug. It was performed over the concentration range of $80-240 \mu \mathrm{g} / \mathrm{ml}$. Each, concentration of the injection was injected three times individually and carried out in the HPLC by keeping the constant injection volume. The regression and correlation coefficients are calculated. The results showed a good linear relationship and the peak responses of omeprazole were strictly linear $(\mathrm{r} 2>0.99)$ in the range of concentrations. The slope of the omeprazole in plain omeprazole standard solution, omeprazole in $0.9 \% \mathrm{NaCl}$ and in $5 \%$ dextrose solution was found 2147967, 2158745 and 2093624. The intercept of omeprazole in plain omeprazole standard solution, omeprazole in $0.9 \% \mathrm{NaCl}$ and in 5\% dextrose was found 8560197, 9154275 and 7691475 respectively. The Linearity plots are showed in Fig. 3A, 3B and 3C.

\subsection{Precision}

The intra-day precision was carried out in both samples solutions with each six sample preparations as per method. After completion of the analysis the chromatograms are integrated and calculated. The intermediate precision was performed for three consecutive days for both solutions. The \% RSD was found to be less than 2 and it shows the method was precised one. The results are summarized in Table 1.

\subsection{Accuracy}

The accuracy was performed by standard addition method. The drug recovery was determined in triplicate by spiking with equivalent amount of placebo into each 50\%, 80\%, 100\%, 120\% and $150 \%$ level of the standard concentration and reconstituted with $0.9 \% \mathrm{NaCl}$ and $5 \%$ dextrose solution separately and further dilutions are made as per method. The average percentage recovery of omeprazole was found to be within the limits and it was highly accurate. The accurate responses of the drug are shown in Table 2.

\subsection{Limit of Detection (LOD) and Limit of Quantification (LOQ)}

From the linearity curve the LOD and LOQ was evaluated. The LOD and LOQ of omeprazole sodium were found to be $0.493 \mu \mathrm{g} / \mathrm{ml}$ and $1.414 \mu \mathrm{g} / \mathrm{ml}$ respectively. It shows that the method can be efficiently used for the estimation of omeprazole sodium injection.

\subsection{Robustness}

The robustness of the method was performed by deliberate changes in the mobile phase composition (77:23 \& 73:27), wavelength $( \pm 5 \mathrm{~nm})$, column oven temperature $\left( \pm 5^{\circ} \mathrm{C}\right), \mathrm{pH}( \pm 0.2)$ and flow rate $( \pm 0.15)$. These studies were carried out as per the above changes and the results are found (Table 3) within the acceptance limits. Hence, the method was found to be robust.

\subsection{Specificity}

The method was found to be specific. Peak purity of the omeprazole was analyzed and found 1.0 for standard omeprazole and omeprazole in both $0.9 \%$ sodium chloride and 5\% dextrose reconstituted sample solutions, it proves that there is no interference and co-elution of any other peaks found in the retention time of Omeprazole and the results are showed in Table 4. It shows that there is no interference in the presence of excipients or placebo. The methodology can be suitably employed for the commercial injectable formulation of omeprazole sodium injection to evaluate the compatibility studies.

\subsection{Stability of solution}

The prepared drug sample solution was found to be stable, and it was performed by injecting the sample solution up to 24 hours in interval of every 4 hours. From the study it was concluded that the results are found within the acceptance and hence the analyte was stable for 24 hours in both $0.9 \%$ sodium chloride and 5\% dextrose reconstituted solutions. The results are showed in Table 5. 


\section{CONCLUSION}

Stability of omeprazole sodium injection in $0.9 \%$ sodium chloride and $5 \%$ dextrose solution was estimated along with method validation by Reverse Phase High Performance Liquid Chromatographic (RPHPLC) technique and carried out successfully. As per the validated study it has been concluded that the present study will be effectively employed to determine the omeprazole in omeprazole sodium injection while reconstituted with $0.9 \%$ sodium chloride and $5 \%$ dextrose solutions. From the validated results it was found that the analyte omeprazole was stable in both solutions.

\section{ACKNOWLEDGEMENTS}

The authors are thankful to Caplin Point Laboratories Limited, Chennai, India and Presidency College, Triplicane (TN), Chennai, India for providing the necessary facilities for the completion of work successfully.

\section{REFERENCES}

[1] Prilosec Prescribing Information. AstraZeneca Pharmaceuticals, Available online at: http://www1.astrazenecaus.com/pi/Prilosec.pdf, 2012.

[2] M. Vaz-Da-Silva, A. I. Loureiro, T. Nunes, J. Maia, S. Tavares, A. Falcao, P. Silveira, L. Almeida, Bioavailability and bioequivalence of two enteric-coated formulations of omeprazole in fasting and fed conditions, Clinical Drug Investigation, 25(6), 2005, 391-399.

[3] Available online at: http://www.drugbank.ca/drugs/DB00338\#pharmacology, 2005

[4] Y. X. Yang, J. D. Lewis, S. Epstein, D. C. Metz, Long-term proton pump inhibitor therapy and risk of hip fracture, JAMA, 296(24), 2006, 2947-2953.

[5] A. Riedel, C. S. Leopold, Quantification of omeprazole degradation by enteric coating polymers: an UV-VIS spectroscopy study, Pharmazie, 60(2), 2005, 126-130.

[6] D. Kumaraswamy, B. S. Rathinaraj, C. H. Rajveer, S. Sudharshini, B. Shrestha, Statistical assurance of process validation by analytical method development and validation for omeprazole capsules and blend, Research Journal of Pharmaceutical, Biological and Chemical Sciences, 1(3), 2010, 50-54.

[7] D. Yaswanth Kumar, K. S. S. N. Neelima, V. Ravinder, M. Rajesh, Simultaneous estimation of Omeprazole, magnesium and domperidone tablets by ultraviolet spectroscopy, PHARMANEST - An International Journal of Advances In Pharmaceutical Sciences, 2(2-3), 2011, 207-210.

[8] K. Karljikovic-Rajic, D. Novovic, V. Marinkovic, D. Agbaba, First-order UV-derivative spectrophotometry in the analysis of omeprazole and pantoprazole sodium salt and corresponding impurities, Journal of Pharmaceutical and Biomedical Analysis,32(4-5), 2003, 1019-1027.

[9] L. P. Kothapalli, V. C. Dewoolkar, A. G. Banerjee, A. B. Thomas, R. K. Nanda, A. D. Deshpande, V. A. Hurne, Simultaneous spectrophotometric estimations of drotaverine hydrochloride and omeprazole, International Journal of ChemTech Research, 2(1), 2010, 493-498.

[10] A. Bhandage, A. Bhosale, A. Kasture, V. P. Godse, Extractive Spectrophotometric Determination of Omeprazole in Pharmaceutical Preparations, Tropical Journal of Pharmaceutical Research, 8(5), 2009, 449-454.

[11] H. Salema, S. M. Riad, M. Reda, K. Ahmed, Simultaneous determination of omeprazole, tinidazole and clarithromycin in bulk powder and Helicure tablets by TLC densitometric technique, Journal of Pharmaceutical Education and Research,4(1), 2013, $34-40$.

[12] W. K. Kang, D. S. Kim, K. I. Kwon, Advanced method for determination of omeprazole in plasma by HPLC, Archieves of Pharmaceutical Research, 22(1), 1999, 86-88.

[13] Z. Dedania, R. Dedania, V. Karkhanis, G. V. Sagar, M. Baldania, N. R. Sheth, RP-HPLC Method for Simultaneous Estimation of Omeprazole and Ondansetron in Combined Dosage Forms, Asian Journal of Research Chemistry, 2(2), $2009,108-111$.

[14] L. Sivasubramanian, V. Anilkumar, Simultaneous HPLC estimation of omeprazole and domperidone from tablets, Indian Journal of Pharmaceutical Sciences, 69(5), 2007, 674-676.

[15] Z. Li, J. Yao, Z. Zhang, L. Zhang, Simultaneous determination of omeprazole and domperidone in dog plasma by LC-MS method, Journal of Chromatographic Science, 47(10), 2009, 881-884.

[16] R. Kayesh, A. Rahman, M. Z. Sultan, M. G. Uddin, F. Aktar, M. A. Rashid, Development and Validation of a RP-HPLC Method for the Quantification of Omeprazole in Pharmaceutical Dosage Form, Journal of Scientific Research, 5 (2), 2013, $335-342$.

[17] K. S. Nataraj, M. B. Duza, K. Pragallapati, D. K. Kumar, Development and validation of RP-HPLC method for the estimation of omeprazole in bulk and capsule dosage forms, International Current Pharmaceutical Journal, 1(11), 2012, 366-369.

[18] S. Gopalakrishnan, K. Jothy, K. Dhanalakshmi, Analytical method development and validation of HPLC method for the determination of omeprazole in capsule dosage form. Elixir Applied Chemistry, 52, 2012, 11283-11286.

[19] V. Krishnaiah, Y. V. Rami Reddy, Development and validation of HPLC method for simultaneous determination of omeprazole and domperidone. Derpharmachemica. 4(1), 2012, 455-459.

[20] K. Nahar, J. J. Joti, M. A. Ullah, A. Hasan, M. A. K. Azad, A. Hasnat, A Simple RP-HPLC Method for the Determination of Omeprazole in Human Serum and Urine: Validation and Application in Pharmacokinetic Study, Dhaka University Journal of Pharmaceutical Sciences, 8(2), 2009, 123-130.

[21] Q. Song, W. Naidong, Analysis of omeprazole and 5-OH omeprazole in human plasma using hydrophilic interaction chromatography with tandem mass spectrometry (HILIC-MS/MS)-Eliminating evaporation and reconstitution steps in 96-well liquid/liquid extraction, Journal of Chromatography B, 830(1,2), 2006, 135-142.

[22] R. Vijayaraghavan, G. Jayababu, R. Prasad, P. E Thirugnanam, G. Shivkumar, V. T. Sriraam, G. Ramesh Kumar, Bio-Analytical Method Development and Validation for Omeprazole Using LC-MS/MS, International Journal of Pharmaceuticl Sciences and Research, 2(9), 2011, 2475-2481.

[23] Anonymous, ICH Guidelines, Validation of Analytical Procedures: Text and Methodology Q2 (R1), $1996,1-17$.

[24] ICH, Guidance for Industry Q2B Validation of Analytical Procedures: Methodology, 1996, 1-12.

[25] United States Pharmacopeia-National formulary (USP-NF 35) section <1225> Validation of Compendial Procedures, 2010 , 1-10. 
Table 1: Precision data for the analysis

\begin{tabular}{|c|c|c|c|c|}
\hline \multicolumn{5}{|c|}{ 0.9\% Sodium Chloride } \\
\hline \multirow{2}{*}{ Concentration } & \multirow{2}{*}{$\begin{array}{l}\text { Intra-mediate } \\
\text { Precision }\end{array}$} & \multicolumn{3}{|c|}{ Intermediate Precision } \\
\hline & & Day-1 & Day-2 & Day-3 \\
\hline $40 \mu \mathrm{g} / \mathrm{ml}$ & 343748847 & 333261693 & 343494986 & 343488334 \\
\hline $40 \mu \mathrm{g} / \mathrm{ml}$ & 342947053 & 340142352 & 342483475 & 342518135 \\
\hline $40 \mu \mathrm{g} / \mathrm{ml}$ & 343130789 & 340357288 & 342562442 & 332446036 \\
\hline $40 \mu \mathrm{g} / \mathrm{ml}$ & 343729793 & 340686732 & 338150805 & 338216816 \\
\hline $40 \mu \mathrm{g} / \mathrm{ml}$ & 348573950 & 340125624 & 342885997 & 342986003 \\
\hline $40 \mu \mathrm{g} / \mathrm{ml}$ & 343447877 & 340664884 & 340972192 & 340957101 \\
\hline Mean & 344263052 & 339206928 & 341758316 & 340102070 \\
\hline Std Dev & 2135931 & 2922751 & 1954087 & 4207644 \\
\hline$\%$ RSD & 0.62 & 0.86 & 0.57 & 1.23 \\
\hline \multicolumn{5}{|c|}{$5 \%$ Dextrose } \\
\hline $40 \mu \mathrm{g} / \mathrm{ml}$ & 315384991 & 321193443 & 320266147 & 320155139 \\
\hline $40 \mu \mathrm{g} / \mathrm{ml}$ & 315219348 & 322267800 & 320817790 & 321876648 \\
\hline $40 \mu \mathrm{g} / \mathrm{ml}$ & 315871848 & 321240300 & 319906614 & 320665489 \\
\hline $40 \mu \mathrm{g} / \mathrm{ml}$ & 315622423 & 320990875 & 320209663 & 321568452 \\
\hline $40 \mu \mathrm{g} / \mathrm{ml}$ & 316102768 & 321471220 & 320926240 & 321658423 \\
\hline $40 \mu \mathrm{g} / \mathrm{ml}$ & 314100427 & 319468879 & 321314019 & 325489761 \\
\hline Mean & 315383634 & 321105419 & 320573412 & 321902319 \\
\hline Std Dev & 705143 & 916762 & 529915 & 1877431 \\
\hline$\%$ RSD & 0.22 & 0.29 & 0.16 & 0.58 \\
\hline
\end{tabular}

Table 2: Summarized Analysis of Accuracy study

\begin{tabular}{|c|c|c|c|c|c|c|}
\hline \multirow{2}{*}{$\begin{array}{l}\text { Accuracy } \\
\text { Level }(\%)\end{array}$} & \multicolumn{2}{|c|}{ Amount Added (mg) } & \multicolumn{2}{|c|}{ Amount Recovered (mg) } & \multicolumn{2}{|c|}{ *Mean Recovery (\%) } \\
\hline & $0.9 \% \mathrm{NaCl}$ & $5 \%$ Dextrose & $0.9 \% \mathrm{NaCl}$ & $5 \%$ Dextrose & $0.9 \% \mathrm{NaCl}$ & $5 \%$ Dextrose \\
\hline \multirow{3}{*}{50} & 20.17 & 19.42 & 20.12 & 19.56 & \multirow{3}{*}{99.85} & \multirow{3}{*}{100.85} \\
\hline & 20.07 & 19.61 & 20.15 & 19.83 & & \\
\hline & 20.22 & 19.46 & 20.10 & 19.60 & & \\
\hline \multirow{3}{*}{80} & 32.71 & 32.24 & 32.24 & 32.24 & \multirow{3}{*}{101.39} & \multirow{3}{*}{100.41} \\
\hline & 32.68 & 31.17 & 32.17 & 31.30 & & \\
\hline & 32.58 & 31.22 & 32.22 & 31.49 & & \\
\hline \multirow{3}{*}{100} & 39.68 & 39.55 & 39.75 & 39.55 & \multirow{3}{*}{99.45} & \multirow{3}{*}{99.74} \\
\hline & 39.58 & 39.05 & 40.00 & 39.05 & & \\
\hline & 39.67 & 39.04 & 39.84 & 39.04 & & \\
\hline \multirow{3}{*}{120} & 48.42 & 47.93 & 48.23 & 47.76 & \multirow{3}{*}{100.77} & \multirow{3}{*}{99.67} \\
\hline & 48.56 & 47.84 & 48.14 & 47.60 & & \\
\hline & 48.60 & 47.09 & 48.09 & 47.03 & & \\
\hline \multirow{3}{*}{150} & 60.02 & 59.02 & 59.16 & 58.82 & \multirow{3}{*}{98.62} & \multirow{3}{*}{99.51} \\
\hline & 59.84 & 59.14 & 59.13 & 58.67 & & \\
\hline & 60.03 & 59.27 & 59.11 & 59.05 & & \\
\hline
\end{tabular}

*Average of three observations 
A Validated Stability of Omeprazole Sodium...

Table 3: Summarized data of Robustness

\begin{tabular}{|c|c|c|c|c|c|}
\hline \multirow{2}{*}{ Parameter Name } & \multirow{2}{*}{ Condition } & \multicolumn{2}{|c|}{ Tailing factor } & \multicolumn{2}{|c|}{$\%$ RSD } \\
\hline & & $\% 0.9 \mathrm{NaCl}$ & $5 \%$ Dextrose & $\% 0.9 \mathrm{NaCl}$ & $5 \%$ Dextrose \\
\hline \multirow{2}{*}{ Wave Length (nm) } & 282 & 1.12 & 1.10 & 0.84 & 0.21 \\
\hline & 278 & 1.15 & 1.13 & 0.83 & 0.29 \\
\hline \multirow{2}{*}{ Mobile Phase variation (v/v) } & $77: 23$ & 1.19 & 1.17 & 0.06 & 0.22 \\
\hline & $73: 27$ & 1.07 & 1.06 & 0.06 & 0.32 \\
\hline \multirow{2}{*}{$\mathrm{pH}$} & 7.0 & 1.06 & 1.08 & 0.11 & 0.16 \\
\hline & 7.4 & 1.14 & 1.017 & 0.10 & 0.28 \\
\hline \multirow{2}{*}{ Flow Rate $(\mathrm{ml})$} & 1.35 & 1.21 & 1.24 & 0.01 & 0.25 \\
\hline & 1.65 & 1.10 & 1.09 & 0.10 & 0.22 \\
\hline \multirow{2}{*}{ Column Temperature $\left({ }^{\circ} \mathrm{C}\right)$} & 25 & 1.21 & 1.23 & 0.02 & 0.10 \\
\hline & 35 & 1.09 & 1.11 & 0.03 & 0.27 \\
\hline
\end{tabular}

*Average of three determinations

Table 4: Specificity study of Omeprazole

\begin{tabular}{|c|l|c|c|}
\hline S. No. & \multicolumn{1}{|c|}{ Name } & RT & Peak purity \\
\hline 1 & Standard Omeprazole & 11.053 & 1 \\
\hline 2 & Omeprazole sodium in $0.9 \% \mathrm{NaCl}$ & 11.147 & 1 \\
\hline 3 & Omeprazole sodium in 5.0\% Dextrose & 11.174 & 1 \\
\hline
\end{tabular}

Table 5: Summarized study of Stability investigation

\begin{tabular}{|c|c|c|c|c|c|}
\hline \multirow{2}{*}{ S. No. } & \multirow{2}{*}{ Time point } & \multicolumn{2}{|c|}{ Peak Area } & \multicolumn{2}{c|}{ Difference in Area\% } \\
\cline { 3 - 5 } & & $\mathbf{\% 0 . 9}$ NaCl & $\mathbf{5 \%}$ Dextrose & \% 0.9 NaCl & 5\% Dextrose \\
\hline 1 & Zero hour & 374217950 & 315050108 & 0.000 & 0.000 \\
\hline 2 & $4^{\text {th }}$ hour & 377688378 & 317367956 & 0.927 & 0.735 \\
\hline 3 & $8^{\text {th }}$ hour & 378607640 & 318170768 & 1.173 & 0.990 \\
\hline 4 & $12^{\text {th }}$ hour & 379479037 & 318729180 & 1.406 & 1.167 \\
\hline 5 & $16^{\text {th }}$ hour & 378267415 & 318877459 & 1.082 & 1.214 \\
\hline 6 & $20^{\text {th }}$ hour & 379852454 & 318138456 & 1.506 & 0.980 \\
\hline 7 & $24^{\text {th }}$ hour & 380222381 & 318271366 & 1.605 & 1.022 \\
\hline
\end{tabular}<smiles>COc1ccc2[nH]c(S(=O)Cc3ncc(C)c(OC)c3C)nc2c1</smiles>

Fig. 1: Structure of Omeprazole

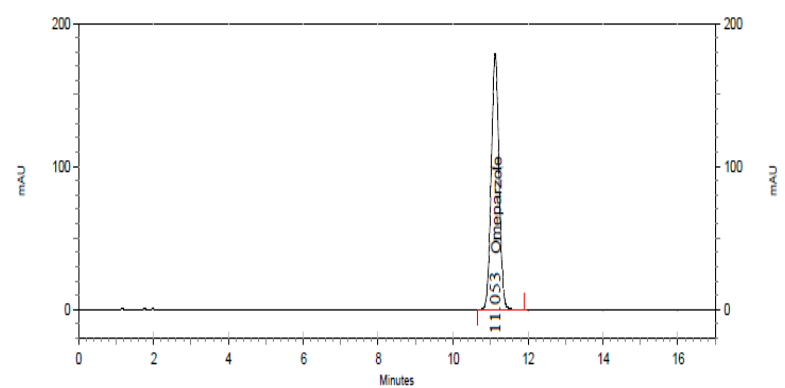

(2A) 


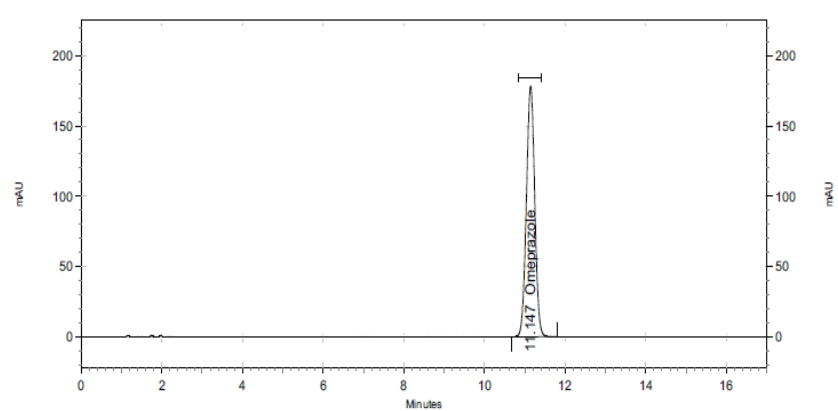

(2B)

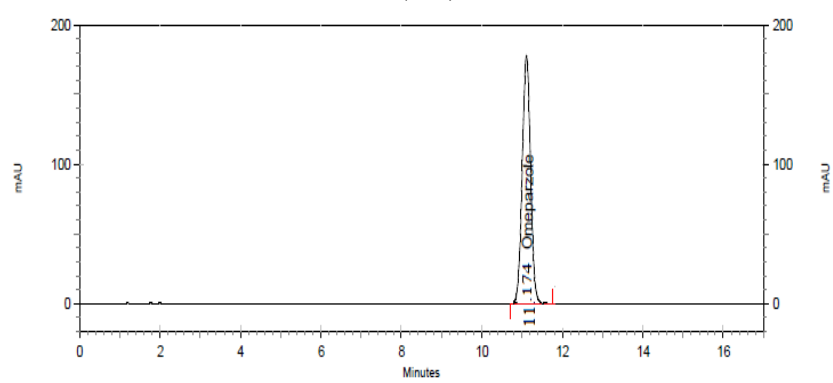

(2C)

Fig. 2: Chromatogram of Omeprazole with (2A) Standard Chromatogram (2B) $0.9 \%$ Sodium Chloride, and (2C) $5 \%$ Dextrose

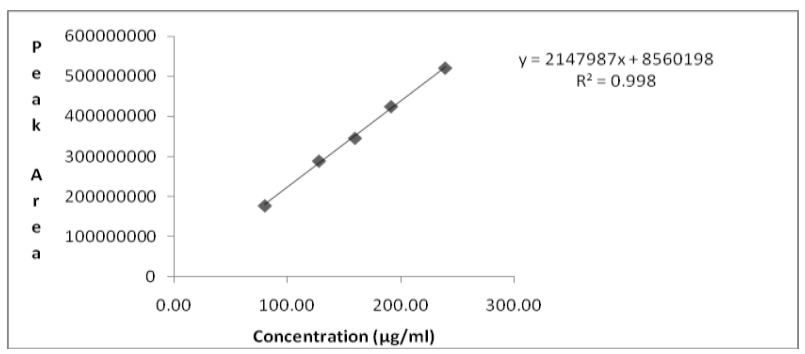

(3A)

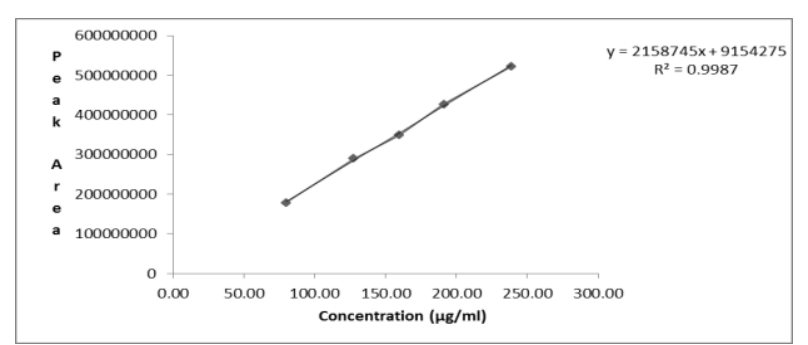

(3B)

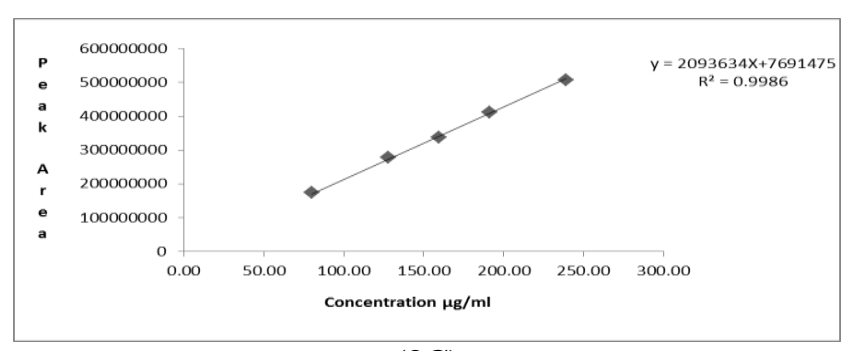

(3C)

Fig. 3: Linearity of Omeprazole in (3A) Standard Solution (3B) 0.9\% Sodium Chloride solution, and (3C) 5\% Dextrose solution 